\title{
The sustainability challenge of meeting carbon dioxide targets in Europe by 2020
}

\section{Saikku, L.}

Elsevier

2008

Saikku et al. 2008. The sustainability challenge of meeting carbon dioxide targets in Europe pÿby 2020. Energy Policy 36(2): 730 742. (Final draft version, post-refereeing)

http://hdl.handle.net/1975/7718

http://dx.doi.org/10.1016/j.enpol.2007.10.007

Downloaded from Helda, University of Helsinki institutional repository.

This is an electronic reprint of the original article.

This reprint may differ from the original in pagination and typographic detail.

Please cite the original version. 


\title{
The sustainability challenge of meeting carbon dioxide targets in Europe by 2020
}

\author{
Laura Saikku', Aapo Rautiainen, Pekka E. Kauppi \\ Department of Biological and Environmental Sciences, University of Helsinki, P.O. Box 27, FIN-00014 Helsinki, Finland \\ Received 23 August 2007; accepted 10 October 2007
}

\begin{abstract}
Following the Kyoto Protocol, the European Union obligated itself to lower its greenhouse gas (GHG) emissions $20 \%$ below their 1990 level, by the year 2020. Carbon dioxide is the major GHG. To fulfill this obligation, the nations must meet the sustainability challenge of countering rising population plus affluence with the dematerialization of less energy per GDP plus the decarbonization of less carbon per energy. To test the feasibility of meeting the challenge, we analyzed carbon dioxide emission during 1993-2004. Although emissions in the entire Union grew only by an average of $0.31 \%$ per year, emissions and their drivers varied markedly among the 27 member states. Dematerialization and decarbonization did occur, but not enough to offset the slight population growth plus rapidly increasing affluence. To fulfill its obligation in the next 12 years, the EU27 would have to counter its increasing population and affluence by a combined dematerialization and decarbonization 1.9-2.6 times faster than during 1993-2004. Hence, fulfilling its obligation by addressing fossil carbon emissions alone is very unlikely.
\end{abstract}

Keywords: Decomposition of $\mathrm{CO}_{2}$ emissions; Energy intensity; Carbon intensity

\section{Introduction}

Human-inflicted greenhouse gas (GHG) emissions have caused most of the temperature rise since the middle of the 20th century. Temperatures are expected to further increase (IPCC, 2007). In 1996, the European commission recommended that rise in global temperature should be limited to $2^{\circ} \mathrm{C}$ above the pre-industrial level. In March 2007, the EU Prime Ministers agreed upon a post-Kyoto target, a commitment of a $20 \%$ reduction of GHG emissions during 1990-2020. On the condition that other countries also commit to reductions, they agreed that the EU countries should reduce GHG emissions by $30 \%$ for the period. However, specic details on how the common reduction burden would be shared between member states should still be decided. Also, it has not been decided how the mitigation measures will address $\mathrm{CO}_{2}$, other GHGs and land cover sinks. The $\mathrm{CO}_{2}$ emissions from combustion of fossil fuels are responsible for approximately three-quarters of all GHG emissions.

Currently, the European Union consists of 27 member states that altogether account for approximately $16 \%$ of global $\mathrm{CO}_{2}$ emissions (EIA, 2007; EEA, 2007). The enlargement of the European Union is only one of the profound historical changes that have shaken the continent over the past two decades. In the early 1990s, the collapse of the Soviet Union, the dissolution of the iron curtain and the war in former Yugoslavia transformed the map of Europe.

This study looks at European $\mathrm{CO}_{2}$ emissions during 1993-2004 and includes in the analysis all current 27 member states, here referred to as EU27. In the early 1990s the union only comprised 12 countries. Austria, Finland and Sweden entered the Union in 1995. Later, in 2004, the Union expanded again as Cyprus, Malta and eight Central and East European countries entered the EU. Finally, the EU attained its current form, when Romania and Bulgaria joined the community in 2007. In this case, it is practical to treat the European Union as two separate entities: the 15 old member states, which committed themselves to the Kyoto protocol as one

${ }^{1}$ Corresponding author. Tel.: +358 40834 4992; fax: +358 9191 58462. E-mail address: laura.saikku@helsinki.. (L. Saikku). 
group, hereafter referred to as EU152, and the 12 more recent arrivals, hereafter referred to as New Member States, or NMS12 ${ }^{3}$.

The total population of EU27 nations in 2004 was estimated at approximately 486 million (Eurostat, 2007a). At the same time, real GDP measured in constant prices (year 2000 international dollars as reported in the Penn World Table, Heston et al., 2007) was approximately $\$ 1.06 \_10_{13}(10.6$ trillion), or around $\$ 21,800$ per capita. In 2004, total energy consumption was approximately 1170 MToe (EEA, 2007).

The total $\mathrm{CO}_{2}$ emissions within the region, excluding land use and land use change, amounted to approximately 1172 teragrams (Tg) of carbon in 2004. In 1990, EU27 states emitted $1207 \mathrm{Tg}$ of C, but the emissions declined markedly by year 1993 to $1126 \mathrm{Tg}$. For the rest of the decade the annual emissions remained fairly constant, but in the beginning of the new millennium, however, regional emissions quickly rebounded. During the years 19902004, total GHG emissions in EU15 countries decreased in most sectors, especially waste management, industrial processes and agriculture (EEA, 2006). Although over the same period of time EU15 transport missions continued to grow (+26\% altogether), GHG emissions caused by energy consumption (excluding transport) decreased by $2 \%$.

\subsection{Study objectives}

We examine the contribution of changing population, income, consumption and technology to observed changes in national $\mathrm{CO}_{2}$ emissions within EU27 over the years 1993-2004, referred to below as the "study period". The numerical analyses of this study refer to $\mathrm{CO}_{2}$ emissions from fossil-fuel combustion and industrial processes. We apply population scenarios up to the year 2020 as prepared by Eurostat and develop simple economic scenarios in order to estimate a baseline for the required improvements in dematerialization and decarbonization given the EU target of $-20 \%$ cut by 2020 . We ask, what kind of improvements in energy and carbon intensity are required in EU27 in order to reach a reduction of $20 \%$ in $\mathrm{CO}_{2}$ emissions by 2020 , and how do the requirements compare to the respective historical improvements as observed. Finally, we discuss the results in relation to opportunities to address other GHGs and land cover sinks within EU27 countries.

\section{Materials and methods}

We use the ImPACT model to decompose $\mathrm{CO}_{2}$ emissions in our analysis (Waggoner and Ausubel, 2002). It is a simple mathematical identity used for describing and predicting the effects of changes in population, affluence, technology, and the intensity of consumption on change in the environment. ImPACT is a reformulation of the IPAT model, first introduced by Ehrlich and Holdren (1971).

Variants of IPAT and ImPACT have been used e.g. by Cole and Neumayer (2004) to estimate the population elasticity of $\mathrm{CO}_{2}$ emissions, by Fan et al. (2006) to analyze the impact factors of $\mathrm{CO}_{2}$ emissions in a stochastic model and by O'Neill et al. (2001) for projecting future $\mathrm{CO}_{2}$ emissions. The effect of population growth on the willingness to implement a reduction of $\mathrm{CO}_{2}$ emissions has been discussed by York (2005). The development of $\mathrm{CO}_{2}$ emissions and its drivers is also discussed in numerous other studies. Other decomposition analyses for $\mathrm{CO}_{2}$ emissions have been conducted e.g. by Sun (2004), Kawase et al. (2006) and EEA (2006). Raupach et al. (2007) studied the trends and drivers of $\mathrm{CO}_{2}$ emissions at the global and regional scale, decomposing emissions to population, affluence, energy intensity of gross domestic product and carbon intensity of energy. They discuss EU as one region, but exclude Bulgaria and Romania, and the Baltic States of the Former Soviet Union.

\subsection{The ImPACT identity and its application}

In the ImPACT identity, total environmental impact I is determined as the product of four drivers, $\mathrm{P}$-population, A—affluence, C—consumers' intensity of use and T—technologists' intensity of emission (Table 1):

\footnotetext{
${ }^{2}$ EU15 = Austria, Belgium, Denmark, Finland, France, Germany, Greece, Ireland, Italy, Luxembourg, Netherlands, Portugal, Spain, Sweden, UK

${ }^{3}$ NMS12 = Bulgaria, Cyprus, Czech R., Estonia, Hungary, Lithuania, Malta, Poland, Romania, Slovak R., Slovenia.
} 


$$
I=P \times A \times C \times T
$$

where I is measured by $\mathrm{CO}_{2}$ emission, $\mathrm{P}$ by population, A by GDP per capita, $\mathrm{C}$ by intensity of energy/GDP and $\mathrm{T}$ by $\mathrm{CO}_{2}$ /energy. Lowercase letters $\mathrm{p}, \mathrm{a}, \mathrm{c}$ and $\mathrm{t}$ represent the annual percentage changes of the four drivers, which add to the change $\mathrm{i}$ of impact. Thus, the Identity dissects the contribution by each of the four drivers to changing the impact, up or down.

Table 1: Attributes of $\mathrm{CO}_{2}$ emissions and variables that cause them

\begin{tabular}{lll}
\hline Symbol & Attribute & Dimension \\
\hline \multicolumn{2}{l}{ State variables } & \\
I & Impact & Tons of carbon \\
$\mathrm{P}$ & Population & Capita \\
$\mathrm{A}$ & Affluence & GDP/capita \\
$\mathrm{C}$ & Consumers' intensity of use & Toe/capita \\
$\mathrm{T}$ & Technologists' intensity of emissions & Tons of C/Toe \\
& & \\
Rates of change & \\
& & \\
$p$ & population change & Capita $(\% / \mathrm{yr})$ \\
$a$ & affluence change & GDP/capita $(\% / \mathrm{yr})$ \\
$c$ & dematerialization in terms of energy & Toe/capita $(\% / \mathrm{yr})$ \\
$t$ & decarbonization & Tons of carbon/Toe $(\% / \mathrm{yr})$ \\
\hline
\end{tabular}

To smooth out annual variation and abnormal values at the very beginning or at the very end of the time series, the overall "average" rate of change for each geographical entity was calculated (formulae (4)-(8), Appendix A). The capital letters were solved for using 3-year averages for carbon emissions, population, GDP and energy consumption at the beginning and at the end of the study period. Then, the average annual rate of change in each component was solved for by dividing the total log\% by the length of the studied time period, correcting for the "lost years" at both ends of the period. In this way the components maintain their multiplicative nature, and their average rates of change add up to i. Three-year averages for the totals (i.e. total energy consumption or total emissions of $\mathrm{CO}_{2}$ ) are used in the calculation of the components to guarantee that the equation remains an identity. If average annual changes were calculated using 3-year averages of $P, A, C$ and $T$, this advantageous feature would be lost.

The total energy consumption figures for EU27 countries are utilized, although emissions are thought to be generated only in combustion processes of fossil fuels. Thus, changes in intensity of emissions, T, imply changes in combustion processes (efficiency, type of process, etc.), but also structural changes in the energy system, such as changes in the mix of fuels, and changes in the proportions of other energy forms, such as nuclear power, hydropower and imported electricity. The structural composition of the economy affects the intensity of use, C. Also, the actual energy efficiency of the output in energy sector affects C. Farla and Blok (2000) found that, in the Netherlands, dematerializations within sectors rather than a shift among sectors produced the national dematerialization of energy consumption lagging economic output.

\subsection{Historical data}

The study period covers years 1993-2004, with extensive panel data available for EU27 member states. Data for $\mathrm{CO}_{2}$ emissions excluding land use, land-use change and forestry were obtained from EEA (2007) and are reported in $\mathrm{Tg}$ of carbon. The historical time series extends from 1993 to 2005. Energy consumption data for years 1993-2005 were also extracted from Eurostat (2007b). Historical population data for the years 1993-2006 were similarly extracted from Eurostat (2007a). Data for GDP were obtained from Penn World Table for years 1993-2004 and are reported at constant prices in year 2000 international dollars (Heston et al., 2007). 


\subsection{Scenario analysis}

Scenario analyses are here developed for the whole EU27 as one body. Designing more precise, countryspecific assessments on the development of the emission intensity and the intensity of use would require knowledge of the distribution of the reduction burden and the means that each country adopts to obtain these goals. We adopt the sustainability challenge approach (Waggoner and Ausubel 2002) to assess the stringency of the required reductions. In other words, our intention is to find a plausible range for the annual rate of emission intensity and intensity of use $(c+t)$ required to reach the European Union's reduction target by 2020, assuming reasonable scenarios for the development of population and affluence.

For the future development of population, three projections are adopted from Eurostat (2007a). The population projections kick off where historical population data end, in the year 2006. All three projections use 2004 as their base year. The Eurostat "baseline variant" projection is our best guess for the future development of population in all EU27 countries. Population is projected to increase from 489 million in 2006 to 496 million in 2020. To offer a comparison for this projection, we use Eurostat's high population and low population variants. In the high population variant population increases from 490 in 2006 to 516 million in 2020 and in the low population variant it decreases from 488 in 2006 to 479 million by 2020.

Values for 2006-2008 $\mathrm{CO}_{2}$ and energy consumption are extrapolated by continuing the average development trend of emissions observed in the last 5 years of historical data. The time series of real GDP was extended to the years 2005-2006 using real GDP growth rates as reported by Eurostat (2007c), and to 2007-2008 by using forecasts reported in the same source.

There are differences between EU27 countries in the economic growth potential in the near future. We make several strong assumptions on how the economies might develop. For projections of the development of total GDP after 2008, countries are divided into four groups based on the level of their affluence (A) in 2006, the last year with historical data for GDP and population. The first group ${ }^{4}$ consists of affluent countries, where $A$ is at least $90 \%$ of the average level of EU15. The second group ${ }^{5}$ consists of countries where $A$ is between 70 and $90 \%$, the third group ${ }^{6}$ of countries where $A$ is between $50-70 \%$, and the fourth group ${ }^{7}$ of countries where $A$ is less than $50 \%$ of the EU15 average.

The countries in Group 1 are considered "mature" economies that grow slower in relative terms than economies in Groups 2-4. The real GDP of Group 1 is set to grow at a steady-state growth rate $\left(r_{s s}\right)$, which varies in our forecast model to simulate slower or faster economic growth. In the first four years, 2009-2012, the real GDP growth rates of Group 1 countries converge from their country-specific average in 2004-2008 to the $r_{s s}$, after which growth is maintained at this rate. Affluence or GDP per capita for these countries is defined normally by the volume of GDP and the forecasted population size in that year.

The other three groups of countries are here set to converge to the average affluence level of Group 1, at differing time spans depending on their initial level of affluence. Simultaneously, the growth rate of affluence is set to converge to the steady-state growth rate of "mature" economies. Group 2, which is closest to the affluence level of Group 1, reaches the average affluence level of Group 1 within 15 years. Group 3 countries are given a 20 -year, and Group 4 countries a 25-year, time span of convergence. As the countries in Groups $2-$ 4 converge to the affluence level of the "mature" economies, their economic growth rate also converges to the steady-state growth rate. Since convergence is simulated by the development of income per capita, total real GDP for these countries for each year is calculated by multiplying the forecasted $A$ by the forecasted P.

In our model, levering the steady-state growth rate of mature economies also affects the growth rate of converging economies, as they catch up. Thus, in the model, changing the rate of economic growth in Group 1 also affects the other groups. This allows us to change the overall economic forecast for the region by altering the steady-state growth rate. However, changing the rate does not change the intrinsic structural characteristics

\footnotetext{
${ }_{5}^{4}$ Group 1: Austria, Belgium, Denmark, Finland, France, Germany, Ireland, Luxembourg, Netherlands, Sweden, UK.

${ }^{5}$ Group 2: Cyprus, Italy, Malta, Slovenia, Spain.

${ }^{6}$ Group 3: Czech Republic, Estonia, Greece, Hungary, Latvia, Lithuania, Portugal.

${ }^{7}$ Group 4: Bulgaria, Poland, Romania, Slovakia.
} 
of the model. To keep the economic and population scenarios independent of each other, the economic forecasts are designed using the baseline population variant and are applied as such when combined with high and low population variants.

To find the range of required $\mathrm{c}+\mathrm{t}$, we combine the three different population scenarios from Eurostat (2007a) with five scenarios on economic growth. The baseline for economic growth is a scenario where the steady-state growth of real GDP is set at $2 \%$ a year. In addition to this, we vary the growth rate, giving it values $1 \%, 1.5 \%$, $2.5 \%$ and $3 \%$.

\section{Results}

\subsection{Development of emissions 1993-2004}

Between 1993 and 2004, CO2 emissions in EU27 increased from $1126 \mathrm{Tg}$ of $\mathrm{C}$ to $1172 \mathrm{Tg}$ of $\mathrm{C}$, annually on average by $0.31 \%$ (Fig. 1, Appendices B and C). Affluence (A) in EU27 grew on average $+2.22 \%$ per year and was the strongest driver. Population $(P)$ also grew slightly, with its growth rate averaging $+0.23 \%$ per year. Changes in the intensity of use (energy/GDP) and in intensity of emissions (CO2/energy) had a reducing impact on emissions, on average $-1.46 \%$ and $-0.67 \%$ per year, respectively.

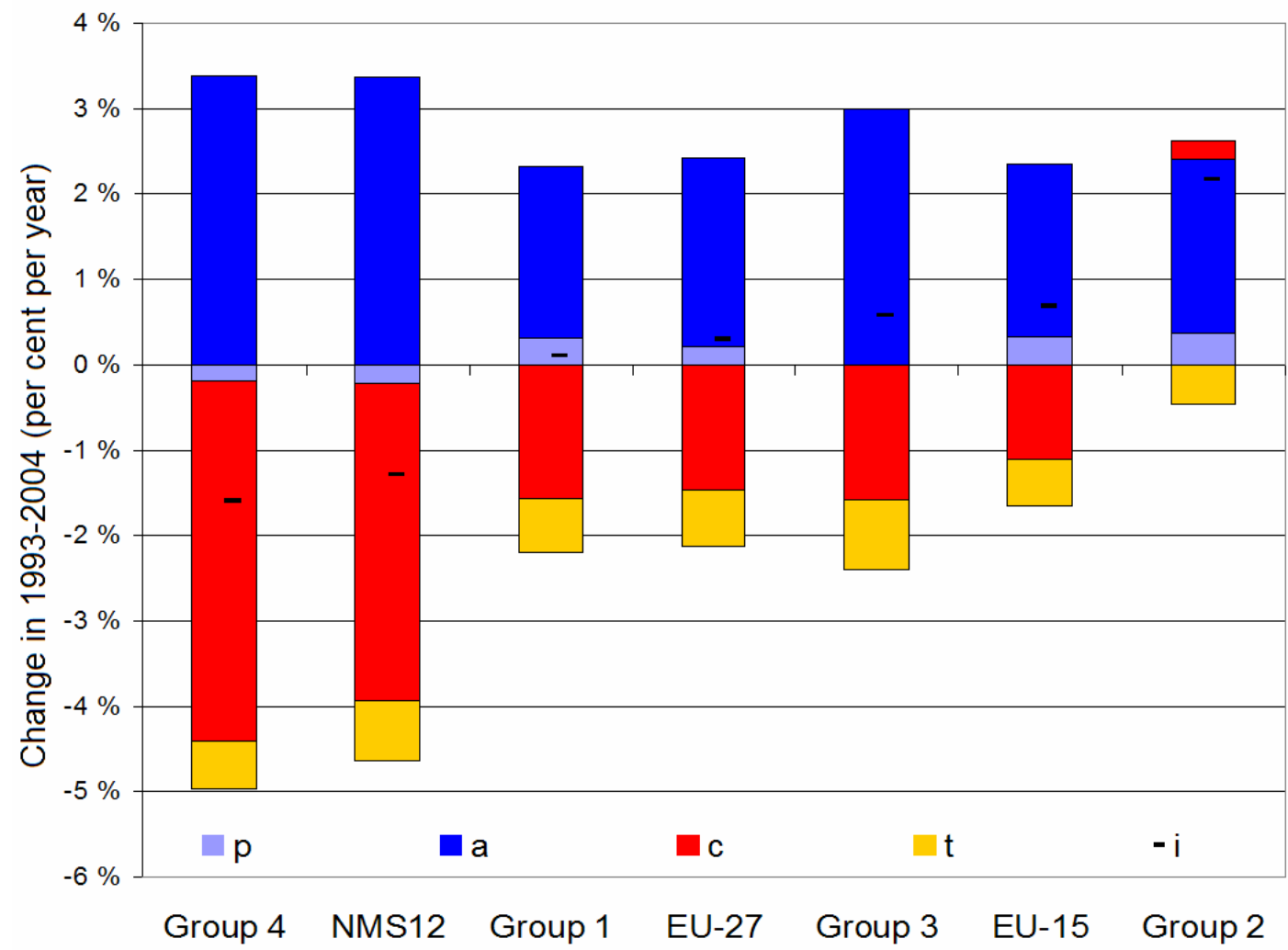

Fig. 1. Average annual changes in emissions, population, affluence, intensity of use and intensity of emissions (1993-2004).

While EU15 emissions increased at a rate of $+0.69 \%$, the emissions in NMS12 decreased by $1.27 \%$ annually on average. In the new member states, declining trends of $c$ and $t$ were sufficient to compensate for the impact of strong economic growth. A negative trend in population also slightly contributed to the declining trend in emissions. In contrast, the population of EU15 slightly increased. Both $\mathrm{c}$ and t were negative also in EU15 states. EU15 accounted for almost $80 \%$, or almost $90 \%$ of the population and economic output, respectively, of the entire EU27 in 2004. The annual decrease of impact in the new member states was absorbed by the stronger West European trend of growing impact, and only slightly mitigated the overall trend for EU27. In 
NMS12 countries, although the rates of dematerialization and decarbonization were high, the state variables C and T (consumers' intensity of use and technologists' intensity of emissions) were about $40 \%$ less advanced than the corresponding estimates for EU15 (Appendix C).

The change of emissions varied between countries (Fig. 2). Emissions increased in all countries in Group 2. In Group 4, the least affluent countries, the growth in population and affluence was offset by development in $c+t$ and the emissions hence decreased. However, rate c+t varied greatly among countries in Group 4 . The patterns in Group 1 and 3 countries were mixed. In the six countries where $\mathrm{CO}_{2}$ emissions reduced fastest (Latvia, Bulgaria, Lithuania, Estonia, Romania, Poland), population shrank and downward forces of $c$ and $t$ were strong, especially so in Latvia and Lithuania (Fig. 3).

Luxembourg, Estonia, Finland, Czech Republic, Belgium and Ireland had the highest $\mathrm{CO}_{2}$ emissions per capita in 2004 (Fig. 2). In three of these countries, Finland, Belgium and Ireland, total emission grew (Appendices B and $\mathrm{C}$ ). In Ireland the strongest upward drivers were changes in population (1.2\%/year) and affluence (6.9\%/year), whereas in Finland affluence grew at an annual rate of $3.5 \%$, while carbon intensity of energy production remained unchanged. In Belgium, population grew at the same rate as in Finland, but, despite slower growth in affluence, the downward drivers ( $c$ and $t$ ) did not suffice to keep emissions in check.

Regarding population in individual EU countries, two distinct trends can be observed. All EU15 countries gained population, although annual rates of change were generally fairly modest (with the exception of Ireland and Luxembourg, where population grew fast). On the other hand, most new member states lost population. Exceptions in this group are Cyprian and Maltese populations, whose annual growth rates were among the highest in Europe. More specifically, the trend of shrinking populations can be pinned down to the East European transition economies. In these countries, population remained constant or grew slightly only in Slovenia and the Slovak Republic. Despite distinct population trends, the population all over Europe changed only little compared to other components included in the identity. Average annual rates of change for all countries fell within a 2.2 percentage point interval, ranging from $-0.9 \%$ in Latvia to $+1.3 \%$ in Cyprus.

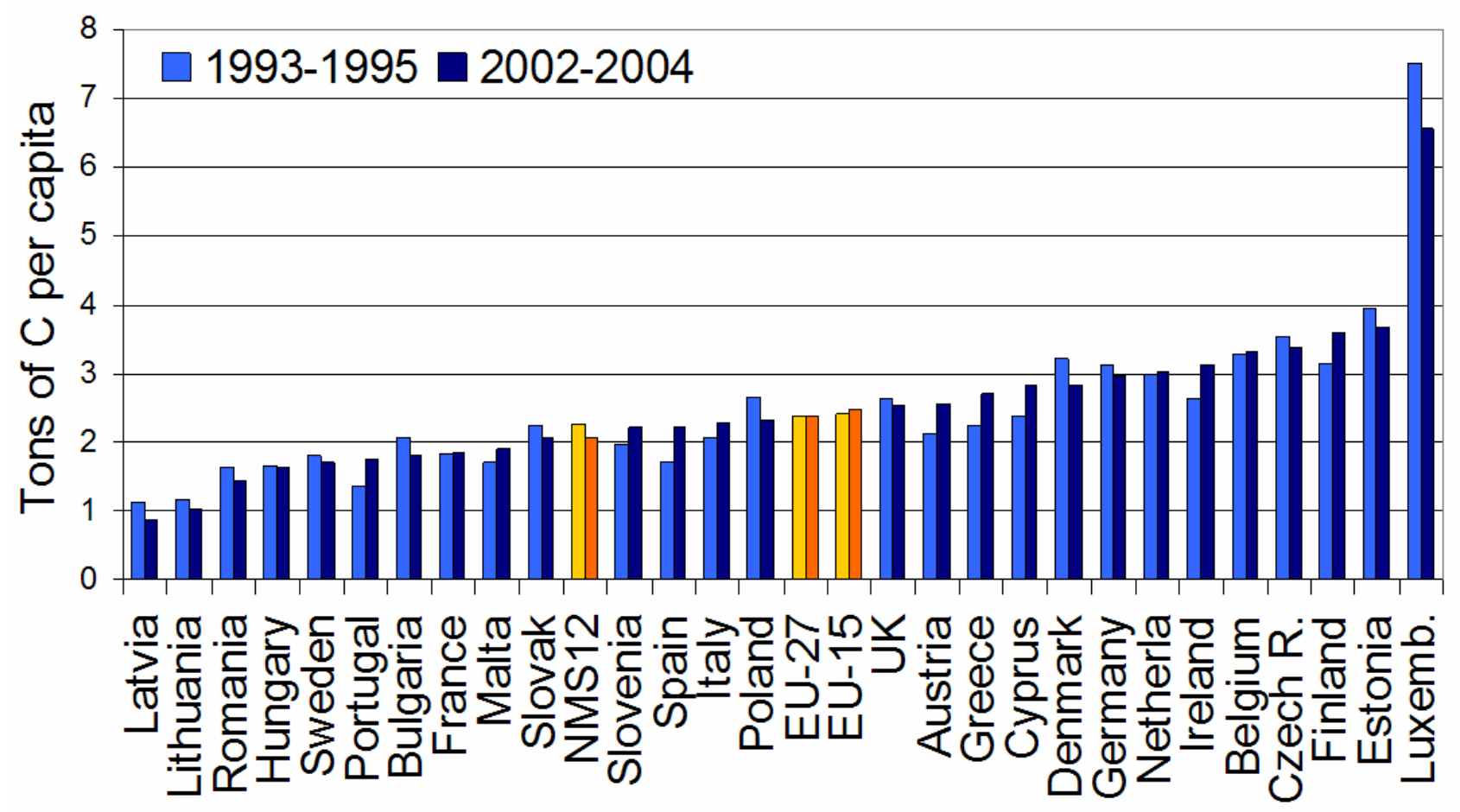

Fig. 2. Average annual CO2 emissions per capita in EU27 at the beginning and the end of the study period. 


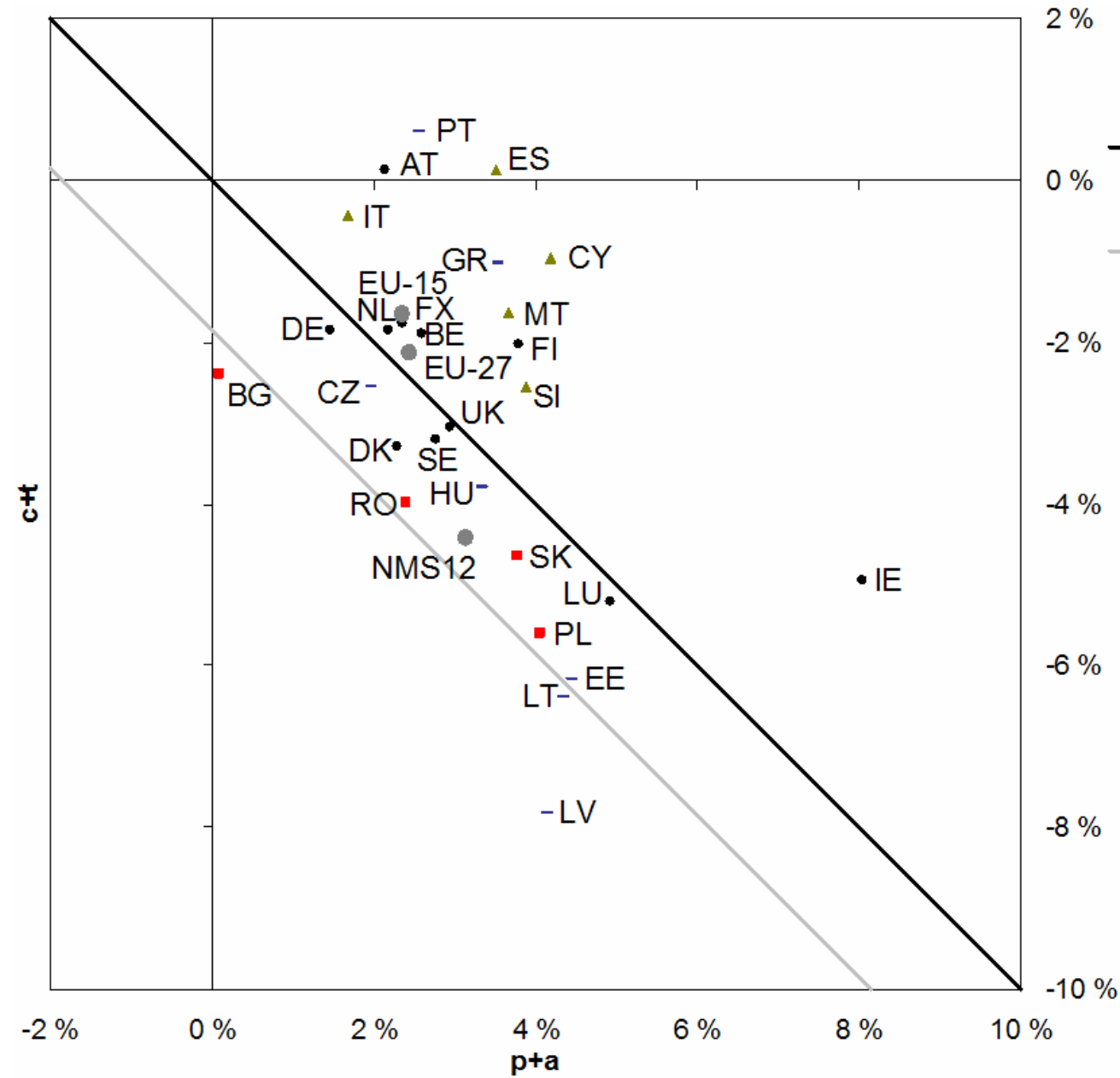

Fig. 3. Changes in population and affluence $(p+a)$, and in dematerialization and decarbonization $(c+t)$ in EU27 countries during 1993-2004 (\%/year). On the chart, nations below the boundary of $(p+a)+(c+t) 1 / 40$ more than met the sustainability challenge of countering population and affluence change $p+a$ with dematerialization and decarbonization $c+t$. Those above the boundary failed. In the example of Ireland, the challenge of $p+a$ was about 8, the progress c+t of 55 carried Ireland more than half the way, but an unmet challenge of 3 remained. The post-Kyoto target of $20 \%$ by 2020 requires still more progress according to our prognosis. In EU27, several nations met the sustainability challenge, but only Bulgaria, Latvia, Lithuania were on track toward the post-Kyoto target, if the observed historical trend is continued.

Average growth of affluence was generally higher in the new member states than in EU15 countries, even though real GDP per capita grew fastest in Ireland (+6.9\% per year) and slowest in Bulgaria $(+0.9 \%)$. All but two NMS12 countries had GDP per capita growth rates above the EU27 median. For aggregate EU15, the growth of affluence peaked in the late 1990s, but slowed down at the turn of the new millennium. On the contrary, apart from great variation in annual growth rates in the early years, economic growth in the NMS12 generally appeared to accelerate towards the end of the period in focus.

For most member states average $c$ was below zero, with the exception of three countries: Portugal (1.9\%), Spain $(0.7 \%)$ and Austria (0.5\%). Italy had no change in C. A regional trend for c can be identified. Generally, dematerialization was faster in new than in old member states. 
Similarly, decarbonization progressed in most countries. Only Malta and Cyprus "recarbonized" $(1.3 \%$ and $0.1 \%$, respectively). No change in T was observed in Finland. Differences in the rates of change between countries were greater in average $c$ than average t. While average $t$ varied between $-3.1 \%$ (in Latvia) and $1.3 \%$ (in Malta), average $\mathrm{c}$ ranged in a greater interval from $-5.9 \%$ in Lithuania to $+1.9 \%$ in Portugal. In terms of $\mathrm{t}$, the difference between old and new member states was not clear-cut. Most EU15 countries tended to scatter around the Union's median rates of improving intensity of use and intensity of emission. The new member states, however, showed a more polarized trend, with three countries among the top five improvers in all of EU27, but also, in terms of $t$, four countries among the five weakest performing states. Throughout EU27, the combined annual improvement in dematerialization+decarbonization - that is, change in $\mathrm{CO}_{2} / \mathrm{GDP}$ - varied greatly: from the fast progress of $-7.8 \%$ in Latvia to the retarding $+0.6 \%$ in Portugal. Ireland was rather unique in terms of high $p$ and high a (Fig. 3, Appendix B).

\subsection{Scenario analysis}

If CO2 emissions in EU27 are to be reduced 20\% below the 1990 level, this will need to happen in 2008-2020, because in 1990-2007 the emissions did not change much. Average annual change of emissions during 12 years needs to be $-1.75 \%$. According to the scenarios for $a$ and $p$ in this study, the annual rate of dematerialization and decarbonization, $c+t$, would need to be between $-4.15 \%$ and $-5.53 \%$ to meet the EU target (Table 2). Approximately in the middle of this interval is the baseline option where population evolves according to Eurostat's baseline variant and the steady-state growth rate $(r)$ is set at $2 \%$ for highly affluent, Group 1 countries. If the region experiences a strong economic downturn or boom within the next 12 years, the sustainability challenge may well be beyond this range. To demonstrate this option, scenarios that incorporate lower and higher economic rates were also included.

Estimating country-specific required annual rates of dematerialization and decarbonization and assessing the likelihood of meeting them would require more detailed information on how the burden is to be shared among the member states. However, compared to the historical development (Fig. 3), the combined rates of c+t would have been sufficient in only three individual countries, should the countries have a unanimous goal of reducing emissions by the same $20 \%$ in 12 years $^{8}$. Of these countries, neither the small Baltic states (Latvia and Lithuania) nor Bulgaria can be considered to be large enough to contribute strongly to the overall development of regional emissions. Of the six most populous countries, only Poland was close to a sufficient rate. Emissions also slightly decreased in Germany and the UK, but kept increasing in France, Italy and Spain. Thus, it is evident that to reach the set emissions' target, $\mathrm{C}$ and T must change fast all over the continent.

\section{Discussion}

Both the theory of climate change mitigation and policy and management applications rely on "efficiency" and "substitution" logic (Robe` rt et al., 2002; World Business Council for Sustainable Development, 2000; Schmidheiny, 1992; Welford, 1998). An estimation of "sustainability challenge" is a common approach in evaluating the stringency of environmental goals and targets. It refers to the smallest required improvement in $C$ and $T$ to compensate the environmental impact of growing population and affluence (Waggoner and Ausubel, 2002). Here we have followed the same approach.

Raupach et al. (2007) studied the global and regional drivers of $\mathrm{CO}_{2}$ emissions. Before the year 2000, in the world as the whole, population and affluence increased at roughly equal rates, and dematerialization and decarbonization occurred, the latter at a slower rate. Changes in $C$ and $T$ were not large enough to compensate the growth in impact induced by changes in $\mathrm{P}$ and $\mathrm{A}$.

Here we investigated in more detail the changes of $P, A, C$ and T within EU27 (small letters $p, a, c, t$ referring to their change). During 1993-2004 in NMS12, high c reflected structural change and can be attributed to growing GDP rather than to decreasing use of energy (Appendix D). Services grew faster than did the more energy-

\footnotetext{
${ }^{8}$ The actual reduction requirement is likely to be slightly less than $20 \%$, since EU27 CO2 emissions in 2008 are projected to be slightly lower than in 1990 .
} 
intensive sectors such as manufacturing and primary production. The energy consumption of manufacturing and primary production declined. Also, the energy consumption of households decreased. The negative population trend (Eurostat, 2007a) may have contributed to the declining energy consumption of households.

Table 2: Required rate of dematerialization and decarbonization, c+t (\%/year), in EU27 during 2008-2020 according to different projections

\section{Projections for economic growth Development of population (Eurostat 2007a)}

\begin{tabular}{llll} 
(steady state growth rate) & Low population variant & Baseline variant & High population variant \\
\hline Slow economic growth (1\%) & -3.73 & -3.98 & -4.30 \\
Slightly lower growth (1.5\%) & -4.15 & -4.39 & -4.71 \\
Baseline scenario (2\%) & -4.56 & -4.81 & -5.12 \\
Slightly higher growth (2.5\%) & -4.97 & -5.22 & -5.53 \\
High economic growth (3\%) & -5.37 & -5.62 & -5.94 \\
\hline
\end{tabular}

In EU15, dematerialization progressed less well than in NMS12. Despite the growing volume of output in manufacturing and primary production, their relative share of GDP declined. The manufacturing sector achieved gains in energy efficiency, while primary production did not. Although the service sector grew more moderately in EU15 than in NMS12, its relative share increased. The value added in service sector was the main driver of economic growth in EU15. The absolute energy consumption of the service sector grew by $17 \%$. This can mainly be attributed to increasing transport. However, intensity of energy use in the service sector (incl. transport) improved by approximately $10 \%$, most of all sectors. The energy consumption of households grew. In EU15, the energy mix changed on lowering t. The share of liquid fuels (oil) decreased from $48 \%$ to $43 \%$, and that of solid fuels from $23 \%$ to $19 \%$, while the share of gas increased from $24 \%$ to $32 \%$. The share of biofuels increased from $4 \%$ to $5 \%$. The combustion efficiency of fuels slightly improved from 97.9 to 97.0 tonCO2/TJ (EEA, 2007), responding mainly to improvements in coal burning. However, total fuel combustion increased by $13 \%$ during 1993-2004 (EEA, 2007). In all three sectors, growth in the absolute volume of energy consumption outweighed the gains in dematerialization and decarbonization. Hence the emissions grew.

The changes in energy mix contributed to the decreasing T. In EU25, between years 1994-2004, the share of $\mathrm{CO}_{2}$-intensive fuels of energy consumption declined: coal from $17.4 \%$ to $13.7 \%$ and oil from $39.7 \%$ to $37.2 \%$ (Eurostat, 2007b). Instead, the shares of natural gas (from 18.4\% to $23.9 \%$ ) and nuclear energy (from $13.8 \%$ to $14.5 \%$ ) increased. Especially in small countries, changes in electricity imports can affect the results.

In Germany, focusing on the largest nations, the energy efficiency of power and heating plants was improved and the economy of the five new La"nder was restructured after reunification. The United Kingdom switched from oil and coal to gas in large scale in electricity production. Italian $\mathrm{CO}_{2}$ emissions increased primarily from road transport, electricity and heat production. In France, $\mathrm{CO}_{2}$ emissions from road transport increased considerably. Spain's emissions responded to the growth on many sectors including electricity and heat production and manufacturing industries. In Poland, as in other new Member States, heavy industry declined in the late 1980s and early 1990s. Transport, especially road transport, increased everywhere and fuel efficiency hardly improved (EEA, 2006).

By 2020, radical improvements of intensity of use and intensity of emissions are required in order to reduce the emissions $20 \%$ below the level of 1990 . A combined annual rate for $\mathrm{c}+\mathrm{t}$ of $-4.15 \%$ to $-5.53 \%$ in the next 12 years is simply too much in our opinion given the inertia of the economy. Such an improvement would mean a 1.9-2.6fold annual rate of dematerialization and decarbonization compared to the latest development ( $2.13 \% / y e a r$ ) within the whole of the EU27 region. Even more radical measures are needed, if the EU aims to reduce GHG emissions by $30 \%$ with this time-table. Reducing $\mathrm{CO}_{2}$ emissions, this would mean an average rate of $2.86 \% / y e a r$. According to the baseline population forecast by Eurostat and our baseline economic projection, the combined rate of $\mathrm{c}+\mathrm{t}$ would need to be $-5.92 \%$, 2.8-fold compared to that in the years 1993-2004. While mitigating the emissions of $\mathrm{CO}_{2}$ from fossil-fuel combustion and industrial processes, the EU must address other 
GHGs and ecosystem sinks. Even so, reducing $\mathrm{CO}_{2}$ emissions by $15 \%(-1.24 \% / y e a r)$ or merely by $10 \%$ ($0.77 \% /$ year) would, according to the baseline projections, mean combined dematerialization and decarbonization of $-4.30 \% / y e a r$ or $-3.83 \% / y e a r$, respectively, thus exceeding the recent rates.

\subsection{Reducing emissions}

Better use of existing technologies will be crucial within the short time horizon toward 2020, since time will not allow large-scale penetration of entirely new technologies. The structure of the economy changes slowly. The volume of manufacturing may shrink in the future if production is transferred to countries where circumstances for industrial production are more favourable; however, such a change might not stand for a reduction in emissions on the global scale (Rothman, 1998). Also, attaining structural change in energy production is slow. Structural change of the energy mix may contribute to reduction efforts, but will hardly be sufficient alone. Finding ways to improve intensity of use and intensity of emissions of transport, along with curbing its volume, is crucial because the transport sector is large and has grown rapidly.

Technologies which reduce the $\mathrm{CO}_{2}$ emissions from coal and gas-burning, such as carbon capture and storage, can be developed. To improve energy efficiency, the Commission proposes tougher standards on appliances: improved energy performance of the EU's existing buildings and improved efficiency of heat and electricity generation, transmission and distribution (European Commission, 2007a). Also, strengthening the EU emission trading system is a proposed action to tackle the emissions (European Commission, 2007b). In order to tackle transport emissions, measures addressing aviation and road traffic can be considered (European Commission, 2007b).

Besides $\mathrm{CO}_{2}$, there are reduction possibilities in other GHGs as well. For example, Delhotal et al. (2006) discuss the ability to significantly reduce methane and nitrous oxide emissions from waste, energy and industrial sectors with current technologies. They stress the low cost of methane and nitrous oxide reductions relative to $\mathrm{CO}_{2}$ reductions.

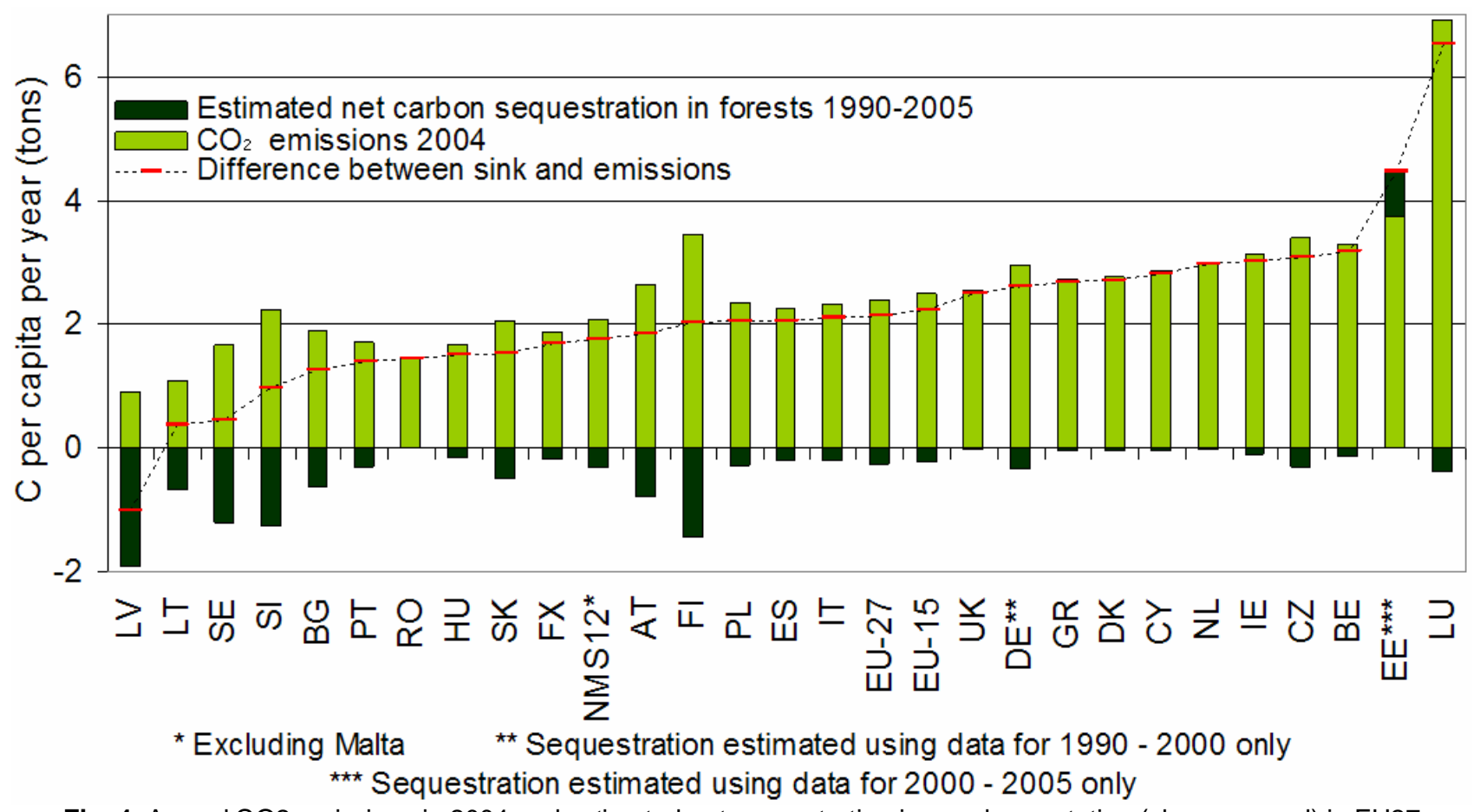

Fig. 4. Annual CO2 emissions in 2004 and estimated net sequestration in woody vegetation (above-ground) in EU27 countries (excl. Malta) in 1990-2005. Data source for estimate: FRA 2005 country tables, growing stock in forest.

Calculations were conducted according to the forest identity (Kauppi et al. 2006) utilizing values $B=0.9$ (ton biomass $/ \mathrm{m} 3$ of growing stock) and $\mathrm{C}=0.5$ (ton carbon/ton dry biomass). Roots or forest soil are not included in the sink estimate. 
Ecosystem sinks can play a role in tackling climate change. During 1990-2005 in EU27, the above-ground tree vegetation expanded at an annual rate of approximately $126 \mathrm{TgC} / \mathrm{year}$, thus absorbing a flux which equals about $11 \%$ of the fossil emissions (Fig. 4). The rate was $10 \%$ and $15 \%$ in EU15 and in NMS12, respectively. The sink in relation to emissions varied greatly among the countries, offsetting the per capita emissions in Latvia and accounting for a large fraction of emissions in Sweden, Lithuania, Slovenia, Finland and Bulgaria. Sequestration is likely to continue, because of the inertia of change in forest area and biomass (Kauppi et al., 2006). Agricultural and forest policies have affected forest trends in the past and can have an effect also during 20082020.

\subsection{Uncertainties}

The ImPACT method identifies the key driving forces behind the emissions. However, the ImPACT method is also susceptible to criticism. For example, CO2/energy as a measure of technology is affected by the changes in the energy mix in addition to changes in the actual technology. Adverse environmental impacts of e.g. imported electricity, nuclear energy, renewable fuels and hydropower are not included in this analysis, but, in reality, they must also be assessed when evaluating the environmental performance of the energy system in a more complete manner. Also, a number of country-specific features like urbanization level and industrial structure are not inherent in this model. However, increasing the amount of attributes would reduce the level of simplicity. Some of the strengths and weaknesses of ImPACT and its variants are discussed e.g. by York et al. (2003).

This study covers only $\mathrm{CO}_{2}$ emissions, not other GHGs. $\mathrm{CO}_{2}$ emissions are better documented than other GHGs, and their link to energy consumption and the standard of living is more direct than is the case with the other GHGs.

The projections developed and used in order to estimate the future development of population and economy add uncertainty to our calculations. It is difficult to predict the regional or country-specific economic cycles that the EU27 will encounter in the next 12 years, or the annual real growth rates of individual countries' economies. However, the policy makers are faced with the same constraints. The model illustrates the difficulty of policy making in such a long term.

There are limitations to the reliability of the economic forecasts, due to the strong structural and dynamic assumptions incorporated in the model. Regarding economic growth, it seems reasonable to expect that East European transition economies grow faster than their West European counterparts, and, compared to historical data, a long-run real GDP growth rate of $2 \%$ for the most affluent countries seems a plausible forecast for the near future. However, the forecast model is sensitive to changes in its structure and the performance of individual countries. Also, strong emission reductions themselves may affect the economy of a country. In this study, however, it was not possible to evaluate such effects.

The structure of the used model asserts that economic growth in converging economies is dependent on the development of the economy in Group 1 countries. In reality, economic performance in Group 1 and Groups 2-4 need not be (and is not) interlinked in this particular way. The simple grouping of countries by affluence level, the predetermined time span of convergence and the dependency structure within in the model, however, help us find rough projections for the EU27 as a whole. Since the predictions are made by combining separate scenarios for the evolution of population and the economy in different countries, the model is rather rigid. Due to a great amount of uncertainty and rigidity, it is not meaningful at this stage to view the economic projections at country level. However, the sensitivity analysis suggests that the rates have to improve compared to the historical record.

\section{Conclusions}

Fossil emissions of CO2 did not change much in Europe in 1993-2004, even though the development of emissions and their drivers varied markedly between member states of the European Union. Changes in the consumers' intensity of use (energy/GDP) and technologists' intensity of emissions (CO2/energy) had a negative impact on emissions, on average $-1.46 \%$ and $-0.67 \% / y e a r$, respectively. However, affluence grew on average $2.22 \% / y e a r$, and population by $0.23 \% /$ year, more than offsetting the efficiency gains. Between countries, $c$ 
varied the most, from $-5.9 \%$ to $1.9 \%$ annually. Also, a varied considerably from $0.9 \%$ to $6.9 \% /$ year and average $t$ from $-3.1 \%$ to $1.3 \%$ /year. Population growth did not vary that much between countries, from $-0.9 \%$ to $1.3 \% / y e a r$.

While the emissions of old member states (EU15) showed an inclining trend of $0.69 \%$, the emissions of new members states (NMS12) decreased by $-1.27 \%$ per year. In NMS12, declining trends of $c$ and t levelled off the impact of strong economic growth. A negative trend in population also slightly contributed to the declining trend in emissions in NMS12. In EU15 both dematerialization and decarbonization made progress but the rates of improvement were modest. The emissions per capita were 16.9\% lower in NMS12 than in EU15 in 2004.

Prospects within the time frame until 2020 of reducing $\mathrm{CO}_{2}$ emissions by $20 \%$ are not good. A declining trend of emissions has not started yet. Time is running short for achieving such an ambitious goal. The reduction in $\mathrm{CO}_{2}$ emissions per output would need to be 1.9-2.6 times faster in the next 12 years compared to that in years 19932004. Therefore, in addition to addressing the fossil emissions, we encourage the national governments of Europe to focus on agricultural and forest policy and waste management in order to address the emissions of non- $\mathrm{CO}_{2}$ green house gases and further to enhance the considerable role of ecosystem biomass as a carbon sink. By 2020, the combined impact of mitigation measures may reduce the European burden on radiative forcing by $20 \%$ or more, even though reaching this goal by addressing fossil $\mathrm{CO}_{2}$ emissions alone is very unlikely.

\section{Acknowledgements}

This study was conducted in conjunction with the project IFEE (Indicator Framework for Eco-Efficiency), which was funded by the Academy of Finland. We gratefully thank Paul E. Waggoner, Gregg Marland and Laura Sokka and Jouni Korhonen for comments on the earlier version of this paper. 


\section{Appendix A}

The formula for the average rate of change in impact, $i$, is

$$
i=\frac{\ln \left(\frac{1}{3} \sum_{j=n-2}^{n} I_{j}\right)-\ln \left(\frac{1}{3} \sum_{k=1}^{3} I_{k}\right)}{n-2}
$$

where $\mathrm{n}$ is the length of the studied time period (in this case 11 years). Respectively, the formulae for the average annual rates of change in the components of $I$ are,

$$
p=\frac{\ln \left(\frac{1}{3} \sum_{j=n-2}^{n} P_{j}\right)-\ln \left(\frac{1}{3} \sum_{k=1}^{3} P_{k}\right)}{n-2}
$$

$$
a=\frac{\ln \left(\frac{\frac{1}{3} \sum_{l=n-2}^{n} \text { real } G D P_{l}}{\frac{1}{3} \sum_{j=n-2}^{n} P_{j}}\right)-\ln \left(\frac{\frac{1}{3} \sum_{m=1}^{3} \text { real GDP } P_{m}}{\frac{1}{3} \sum_{k=1}^{3} P_{k}}\right)}{n-2}
$$

$$
c=\frac{\ln \left(\frac{\frac{1}{3} \sum_{l=n-2}^{n} \text { Energy Consumption }_{l}}{\frac{1}{3} \sum_{j=n-2}^{n} \text { real GDP }}\right)-\ln \left(\frac{\frac{1}{3} \sum_{m=1}^{3} \text { Energy Consumption }_{m}}{\frac{1}{3} \sum_{k=1}^{3} \text { real } G D P_{k}}\right)}{n-2}
$$

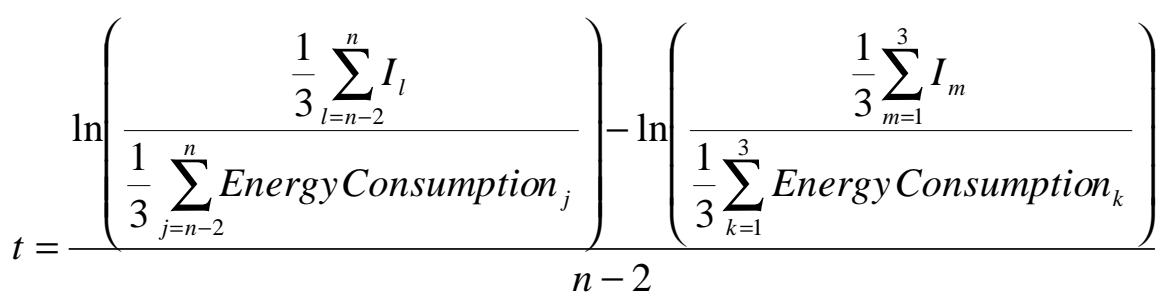




\section{Appendix B}

Average annual rates of change (log\%) in emissions, population, affluence, intensity of use and intensity of emissions (1993-2004) of different countries is shown in Table B1.

Table B1

\begin{tabular}{|c|c|c|c|c|c|}
\hline \multirow[t]{2}{*}{ Country } & \multicolumn{5}{|c|}{ Average annual rates of change $\log \%$} \\
\hline & $\bar{i}$ & $\bar{p}$ & $\bar{a}$ & $\bar{c}$ & $\bar{t}$ \\
\hline Austria & 2.3 & 0.2 & 1.9 & 0.5 & -0.3 \\
\hline Belgium & 0.3 & 0.3 & 1.9 & -1.2 & -0.7 \\
\hline Bulgaria & -2.3 & -0.8 & 0.9 & -2.3 & -0.1 \\
\hline Cyprus & 3.2 & 1.3 & 2.8 & -1.1 & 0.1 \\
\hline Czech Republic & -0.6 & -0.1 & 2.1 & -2.2 & -0.3 \\
\hline Denmark & -1.0 & 0.4 & 1.9 & -1.9 & -1.4 \\
\hline Estonia & -1.7 & -0.9 & 5.3 & -4.9 & -1.2 \\
\hline Finland & 1.8 & 0.3 & 3.5 & -2.1 & 0.0 \\
\hline France & 0.6 & 0.4 & 1.9 & -1.2 & -0.6 \\
\hline Germany & -0.4 & 0.1 & 1.3 & -1.4 & -0.5 \\
\hline Greece & 2.5 & 0.5 & 3.0 & -0.6 & -0.4 \\
\hline Hungary & -0.4 & -0.2 & 3.6 & -2.2 & -1.5 \\
\hline Ireland & 3.1 & 1.2 & 6.9 & -3.7 & -1.3 \\
\hline Italy & 1.3 & 0.1 & 1.5 & 0.0 & -0.4 \\
\hline Latvia & -3.7 & -0.9 & 5.0 & -4.7 & -3.1 \\
\hline Lithuania & -2.0 & -0.6 & 5.0 & -5.9 & -0.5 \\
\hline Luxembourg & -0.3 & 1.2 & 3.7 & -3.3 & -2.0 \\
\hline Malta & 2.0 & 0.9 & 2.8 & -2.9 & 1.3 \\
\hline Netherlands & 0.7 & 0.6 & 2.0 & -1.5 & -0.4 \\
\hline Poland & -1.5 & -0.1 & 4.2 & -5.5 & -0.1 \\
\hline Portugal & 3.2 & 0.5 & 2.1 & 1.9 & -1.3 \\
\hline Romania & -1.6 & -0.2 & 2.6 & -2.5 & -1.5 \\
\hline Slovak Republic & -0.9 & 0.1 & 3.7 & -3.7 & -1.0 \\
\hline Slovenia & 1.3 & 0.0 & 3.8 & -1.4 & -1.1 \\
\hline Spain & 3.6 & 0.7 & 2.8 & 0.7 & -0.6 \\
\hline Sweden & -0.4 & 0.2 & 2.6 & -2.6 & -0.6 \\
\hline UK & -0.1 & 0.3 & 2.6 & -2.3 & -0.7 \\
\hline EU-15 & 0.69 & 0.34 & 2.02 & -1.11 & -0.55 \\
\hline NMS12 & -1.27 & -0.22 & 3.37 & -3.71 & -0.72 \\
\hline EU-27 & 0.31 & 0.22 & 2.22 & -1.46 & -0.67 \\
\hline
\end{tabular}

Countries with negative annual average rates

\begin{tabular}{lllll}
14 & 8 & 0 & 23 & 24 \\
& & & & \\
13 & 18 & 27 & 3 & 2 \\
0 & 1 & 0 & 1 & 1 \\
\hline
\end{tabular}




\section{Appendix C}

Values of components for 3-year averages in carbon emissions, population, GDP and energy consumption is shown in Table C1.

Values of components for three-year averages in Carbon Emissions, Population, GDP and Energy Consumption

\begin{tabular}{|c|c|c|c|c|c|c|c|c|c|c|}
\hline \multirow[t]{2}{*}{ Country } & \multicolumn{5}{|c|}{ At the beginning of study period (1993-1995) } & \multicolumn{5}{|c|}{ At the end of study period (2002-2004) } \\
\hline & I & $\mathrm{P}$ & A & C & $\mathrm{T}$ & $\mathrm{I}$ & $\mathrm{P}$ & A & $\mathrm{C}$ & $\mathrm{T}$ \\
\hline Austria & 16.8 & 7,930 & 23.5 & $10.9 \times 10^{-8}$ & $8.3 \times 10^{-4}$ & 20.6 & 8,106 & 27.8 & $11.4 \times 10^{-8}$ & $8.0 \times 10^{-4}$ \\
\hline Belgium & 33.3 & 10,112 & 21.4 & $15.6 \times 10^{-8}$ & $9.8 \times 10^{-4}$ & 34.3 & 10,368 & 25.4 & $14.1 \times 10^{-8}$ & $9.3 \times 10^{-4}$ \\
\hline Bulgaria & 17.4 & 8,441 & 7.4 & $17.7 \times 10^{-8}$ & $15.9 \times 10^{-4}$ & 14.2 & 7,831 & 8.0 & $14.4 \times 10^{-8}$ & $15.7 \times 10^{-4}$ \\
\hline Cyprus & 1.5 & 639 & 18.3 & $11.5 \times 10^{-8}$ & $11.3 \times 10^{-4}$ & 2.0 & 721 & 23.6 & $10.4 \times 10^{-8}$ & $11.5 \times 10^{-4}$ \\
\hline Czech R. & 36.4 & 10,330 & 12.2 & $20.3 \times 10^{-8}$ & $14.2 \times 10^{-4}$ & 34.5 & 10,208 & 14.7 & $16.7 \times 10^{-8}$ & $13.8 \times 10^{-4}$ \\
\hline Denmark & 16.7 & 5,209 & 23.7 & $11.8 \times 10^{-8}$ & $11.5 \times 10^{-4}$ & 15.2 & 5,388 & 28.1 & $9.9 \times 10^{-8}$ & $10.2 \times 10^{-4}$ \\
\hline Estonia & 5.8 & 1,464 & 8.4 & $22.2 \times 10^{-8}$ & $21.1 \times 10^{-4}$ & 5.0 & 1,354 & 13.6 & $14.2 \times 10^{-8}$ & $19.0 \times 10^{-4}$ \\
\hline Finland & 16.0 & 5,088 & 17.5 & $24.7 \times 10^{-8}$ & $7.3 \times 10^{-4}$ & 18.8 & 5,211 & 24.0 & $20.5 \times 10^{-8}$ & $7.3 \times 10^{-4}$ \\
\hline France & 105.7 & 57,657 & 21.7 & $11.2 \times 10^{-8}$ & $7.5 \times 10^{-4}$ & 111.5 & 59,944 & 25.8 & $10.1 \times 10^{-8}$ & $7.1 \times 10^{-4}$ \\
\hline Germany & 252.8 & 81,424 & 22.5 & $12.0 \times 10^{-8}$ & $11.5 \times 10^{-4}$ & 244.0 & 82,518 & 25.4 & $10.6 \times 10^{-8}$ & $11.0 \times 10^{-4}$ \\
\hline Greece & 23.6 & 10,551 & 12.1 & $12.1 \times 10^{-8}$ & $15.3 \times 10^{-4}$ & 29.6 & 11,017 & 15.9 & $11.5 \times 10^{-8}$ & $14.8 \times 10^{-4}$ \\
\hline Hungary & 17.1 & 10,343 & 9.5 & $16.0 \times 10^{-8}$ & $10.9 \times 10^{-4}$ & 16.4 & 10,135 & 13.1 & $13.1 \times 10^{-8}$ & $9.5 \times 10^{-4}$ \\
\hline Ireland & 9.4 & 3,592 & 15.2 & $14.1 \times 10^{-8}$ & $12.2 \times 10^{-4}$ & 12.4 & 3,985 & 28.3 & $10.2 \times 10^{-8}$ & $10.9 \times 10^{-4}$ \\
\hline Italy & 117.6 & 56,841 & 20.2 & $9.7 \times 10^{-8}$ & $10.6 \times 10^{-4}$ & 131.7 & 57,550 & 23.2 & $9.7 \times 10^{-8}$ & $10.2 \times 10^{-4}$ \\
\hline Latvia & 2.8 & 2,523 & 7.1 & $22.1 \times 10^{-8}$ & $7.2 \times 10^{-4}$ & 2.0 & 2,328 & 11.2 & $14.4 \times 10^{-8}$ & $5.5 \times 10^{-4}$ \\
\hline Lithuania & 4.3 & 3,656 & 7.5 & $17.3 \times 10^{-8}$ & $9.0 \times 10^{-4}$ & 3.5 & 3,456 & 11.7 & $10.2 \times 10^{-8}$ & $8.6 \times 10^{-4}$ \\
\hline Luxembourg & 3.0 & 403 & 35.7 & $23.9 \times 10^{-8}$ & $8.8 \times 10^{-4}$ & 3.0 & 449 & 50.0 & $17.9 \times 10^{-8}$ & $7.4 \times 10^{-4}$ \\
\hline Malta & 0.6 & 368 & 14.8 & $7.9 \times 10^{-8}$ & $14.5 \times 10^{-4}$ & 0.8 & 398 & 19.0 & $6.1 \times 10^{-8}$ & $16.3 \times 10^{-4}$ \\
\hline Netherlands & 45.8 & 15,377 & 21.9 & $13.9 \times 10^{-8}$ & $9.8 \times 10^{-4}$ & 48.8 & 16,211 & 26.2 & $12.1 \times 10^{-8}$ & $9.5 \times 10^{-4}$ \\
\hline Poland & 101.7 & 38,533 & 6.4 & $25.5 \times 10^{-8}$ & $16.1 \times 10^{-4}$ & 88.5 & 38,209 & 9.4 & $15.6 \times 10^{-8}$ & $15.9 \times 10^{-4}$ \\
\hline Portugal & 13.6 & 10,006 & 14.4 & $8.8 \times 10^{-8}$ & $10.8 \times 10^{-4}$ & 18.1 & 10,428 & 17.4 & $10.5 \times 10^{-8}$ & $9.6 \times 10^{-4}$ \\
\hline Romania & 35.9 & 22,211 & 5.0 & $22.2 \times 10^{-8}$ & $14.6 \times 10^{-4}$ & 31.1 & 21,752 & 6.3 & $17.8 \times 10^{-8}$ & $12.7 \times 10^{-4}$ \\
\hline Slovak R. & 12.0 & 5,345 & 7.9 & $25.7 \times 10^{-8}$ & $11.1 \times 10^{-4}$ & 11.1 & 5,380 & 11.0 & $18.5 \times 10^{-8}$ & $10.2 \times 10^{-4}$ \\
\hline Slovenia & 3.9 & 1,990 & 13.7 & $13.8 \times 10^{-8}$ & $10.4 \times 10^{-4}$ & 4.4 & 1,996 & 19.3 & $12.2 \times 10^{-8}$ & $9.4 \times 10^{-4}$ \\
\hline Spain & 66.7 & 39,290 & 16.2 & $9.7 \times 10^{-8}$ & $10.8 \times 10^{-4}$ & 92.4 & 41,888 & 20.8 & $10.4 \times 10^{-8}$ & $10.3 \times 10^{-4}$ \\
\hline Sweden & 15.7 & 8,775 & 21.0 & $18.0 \times 10^{-8}$ & $4.8 \times 10^{-4}$ & 15.2 & 8,953 & 26.4 & $14.2 \times 10^{-8}$ & $4.5 \times 10^{-4}$ \\
\hline UK & 152.4 & 57,868 & 20.5 & $12.0 \times 10^{-8}$ & $10.7 \times 10^{-4}$ & 151.0 & 59,516 & 26.0 & $9.7 \times 10^{-8}$ & $10.1 \times 10^{-4}$ \\
\hline \multirow{4}{*}{$\begin{array}{l}\text { EU-15 } \\
\text { NMS12 } \\
\text { EU-27 }\end{array}$} & 889.3 & 370,124 & 20.3 & $11.8 \times 10^{-8}$ & $10.1 \times 10^{-4}$ & 946.7 & 381,534 & 24.4 & $10.6 \times 10^{-8}$ & $9.6 \times 10^{-4}$ \\
\hline & 239.5 & 105,843 & 7.4 & $21.3 \times 10^{-8}$ & $14.3 \times 10^{-4}$ & 213.6 & 103,768 & 10.1 & $15.3 \times 10^{-8}$ & $13.4 \times 10^{-4}$ \\
\hline & 1128.8 & 475,967 & 17.5 & $12.7 \times 10^{-8}$ & $10.7 \times 10^{-4}$ & 1160.2 & 485,302 & 21.3 & $11.1 \times 10^{-8}$ & $10.1 \times 10^{-4}$ \\
\hline & $\begin{array}{l}\text { I } \\
\text { A } \\
\text { C } \\
\text { T }\end{array}$ & \multicolumn{9}{|c|}{$\begin{array}{l}=\mathrm{CO}_{2} \text { emissions in } \mathrm{Tg} \text { of } \mathrm{C} \\
=\text { Population (thousands) } \\
=\mathrm{GDP} \text { per capita in year } 2000 \text { international } \$ \text { (thousands) } \\
=\text { Energy consumption (TOE) per GDP in year } 2000 \text { international } \$ \\
=\mathrm{CO}_{2} \text { emissions in } \mathrm{Tg} \text { of } \mathrm{C} \text { per Energy consumption (TOE) }\end{array}$} \\
\hline
\end{tabular}




\section{Appendix D}

Different sectors' share of total energy consumption, and increase in absolute volume of consumption 19952005 is shown in Table D1.

\section{Table D1}

\begin{tabular}{|c|c|c|c|c|}
\hline (5) & & $\begin{array}{l}\text { Share of total Energy } \\
\text { consumption } 1995\end{array}$ & $\begin{array}{l}\text { Share of total Energy } \\
\text { consumption } 2005\end{array}$ & $\begin{array}{l}\text { Change in volume of } \\
\text { energy consumption }\end{array}$ \\
\hline \multirow[t]{7}{*}{ EU27 } & Primary production & $3.3 \%$ & $2.8 \%$ & $-6.3 \%$ \\
\hline & Manufacturing & $30.3 \%$ & $27.6 \%$ & $0.0 \%$ \\
\hline & Services (incl. transport) & $38.8 \%$ & $42.2 \%$ & $19.4 \%$ \\
\hline & $\begin{array}{l}\text { Services } \\
\text { transport) }\end{array}$ & $10.6 \%$ & $11.3 \%$ & $16.1 \%$ \\
\hline & Transport & $28.1 \%$ & $31.0 \%$ & $20.7 \%$ \\
\hline & Households & $26.5 \%$ & $26.6 \%$ & $9.8 \%$ \\
\hline & Other & $1.1 \%$ & $0.8 \%$ & $-22.9 \%$ \\
\hline \multirow[t]{7}{*}{ EU15 } & Primary production & $2.8 \%$ & $2.6 \%$ & $3.6 \%$ \\
\hline & Manufacturing & $28.6 \%$ & $27.1 \%$ & $5.9 \%$ \\
\hline & Services (incl. transport) & $41.7 \%$ & $43.5 \%$ & $17.0 \%$ \\
\hline & $\begin{array}{l}\text { Services } \\
\text { transport) }\end{array}$ & $11.0 \%$ & $112 \%$ & $139 \%$ \\
\hline & Transport & $30.7 \%$ & $32.3 \%$ & $18.0 \%$ \\
\hline & Households & $25.8 \%$ & $26.0 \%$ & $13.0 \%$ \\
\hline & Other & $1.1 \%$ & $0.8 \%$ & $-16.0 \%$ \\
\hline \multirow[t]{7}{*}{ NMS12 } & Primary production & $5.9 \%$ & $4.2 \%$ & $-31.4 \%$ \\
\hline & Manufacturing & $39.0 \%$ & $31.0 \%$ & $-22.8 \%$ \\
\hline & Services (incl. transport) & $23.3 \%$ & $34.2 \%$ & $42.7 \%$ \\
\hline & Services & & & \\
\hline & transport) & $8.5 \%$ & $11.5 \%$ & $30.6 \%$ \\
\hline & Transport & $14.8 \%$ & $22.7 \%$ & $49.7 \%$ \\
\hline & $\begin{array}{l}\text { Households } \\
\text { Other }\end{array}$ & $\begin{array}{l}30.2 \% \\
1.5 \%\end{array}$ & $\begin{array}{l}29.7 \% \\
0.8 \%\end{array}$ & $\begin{array}{l}-4.4 \% \\
-48.3 \%\end{array}$ \\
\hline
\end{tabular}

Source: Eurostat, 2007b. 


\section{Appendix E}

Share of different sectors' shares of GDP, and increase in real volume of output 1995-2005 is shown in Table E1.

Table E1

\begin{tabular}{lllll} 
& & Share of GDP 1995 & Share of GDP 2005 & $\begin{array}{l}\text { Change in volume of } \\
\text { value added by sector }\end{array}$ \\
\hline \multirow{2}{*}{ EU27 } & Primary production & $3.8 \%$ & $3.1 \%$ & $3.3 \%$ \\
& Manufacturing & $12.1 \%$ & $10.4 \%$ & $7.9 \%$ \\
& Services (incl. transport) & $66.9 \%$ & $69.1 \%$ & $29.5 \%$ \\
& & & \\
EU15 & Other & $17.3 \%$ & $17.3 \%$ & $25.8 \%$ \\
& Primary production & $3.5 \%$ & $2.9 \%$ & $2.9 \%$ \\
& Manufacturing & $12.0 \%$ & $10.4 \%$ & $7.5 \%$ \\
& Services (incl. transport) & $67.3 \%$ & $69.7 \%$ & $28.8 \%$ \\
& & & \\
NMS12 & $17.1 \%$ & $17.0 \%$ & $23.3 \%$ \\
& Other & & & \\
& Primary production & $10.9 \%$ & $7.9 \%$ & $6.8 \%$ \\
& Manufacturing & $12.4 \%$ & $9.9 \%$ & $17.7 \%$ \\
& Services (incl. transport) & $56.0 \%$ & $57.2 \%$ & $50.4 \%$ \\
& & & $76.9 \%$
\end{tabular}

Source: Eurostat, 2007b. 


\section{References}

Cole, MA., Neumayer, E., 2004. Examining the impact of demographic factors on air pollution. Population \& Environment 26 (1), 5-21.

Delhotal, K.C., Chesnaye, F.C. de la, Gardiner, A., Bates, J., 2006. Mitigation of methane and nitrous oxide emissions from waste, energy

and industry. The Energy Journal, Special Issue 3, 45-62.

EEA, 2006. Greenhouse gas emission trends and projections in Europe 2006. Report No. 9/2006. Luxembourg.

EEA, 2007. Annual European Community greenhouse gas inventory 1990-2005 and inventory report 2007. Technical Report No. 7/2007. European Environment Agency.

Ehrlich, P., Holdren, J., 1971. Impact of population growth. Science 171, 1212-1217.

EIA, 2007. Energy Information Administration. International Energy Annual 2004 /

http://www.eia.doe.gov/pub/international/iealf/tablee1.xlsS.

European Commission, 2007a. An energy policy for Europe. Communication from the Commission. COM (2007)

1. Commission of the

European communities, Brussels/http://ec.europa.eu/energy/energy_policy/documents_en.htmS.

European Commission, 2007b. Limiting global climate change to 21 Celsius: the way ahead for 2020 and beyond. Communication from the Commission. COM (2007) 2. Commission of the European communities, Brussels /

http://ec.europa.eu/environment/climat/future_action.htmS.

Eurostat, 2007a. Eurostat population database; population, population projections.

Eurostat, 2007b. Eurostat energy database; supply, transformation, consumption—all products—annual data.

Eurostat, 2007c. Eurostat data 2007. Real GDP growth rate.

Eurostat, 2007d. National accounts by 31 branches—aggregates at constant prices.

Fan, Y., Liu, L.C., Wu, G., Wei, Y.-M., 2006. Analyzing impact factors of CO2 emissions using the STIRPAT model. Environmental Impact

Assessment Review 26 (4), 377-395.

Farla, J.C.M., Blok, C., 2000. Energy efficiency and structural change in the Netherlands, 1980-1995: influence of energy efficiency, dematerialization, and economic structure on national energy consumption. Journal of Industrial Ecology 4 (1), 93-117.

FRA, 2005. Global forest resources assessment. Forestry Paper 147. United Nations, Rome.

Heston, A., Summers, R., Aten, B., 2007. Penn World Table, Version 6.2. Center for International Comparisons of Production, Income and

Prices at the University of Pennsylvania /http://pwt.econ.upenn.edu/S.

IPCC, 2007. Climate change 2007: the physical science basis. Summary for Policymakers. Contribution of Working Group I to the Fourth Assessment Report of the Intergovernmental Panel on Climate Change. IPCC Secretariat, Switzerland.

Kauppi, P., Ausubel, J., Fang, J., Mather, A., Sedjo, R., Waggoner, P., 2006. Returning forests analysed with the forest identity. Proceedings of the National Academy of Science 103 (46), 17574-17579. 
Kawase, R., Matsuoka, Y., Fujino, J., 2006. Decomposition analysis of CO2 emission in long-term climate stabilization scenarios. Energy Policy 34 (15), 2113-2122.

O'Neill, B.C., MacKellar, F.W., Lutz, W., 2001. Population and Climate Change. Cambridge University Press, Cambridge.

Raupach, M.R., Marland, G., Ciais, P., Le Que' re' , C., Canadell, J.G., Klepper, G., Field, C.B., 2007. Global and regional drivers of accelerating CO2 emissions. Proceedings of the National Academy of Science 104 (24), 10288-10293.

Robert, K.-H., Schmidt-Bleek, B., Aloisi de Larderel, J., Basile, G., Jansen, J.L., Kuehr, R., Price Thomas, P., Suzuki, M., Hawken, P., Wackernagel, M., 2002. Strategic sustainable development-selection, design and synergies of applied tools. Journal of Cleaner Production 10, 197-214.

Rothman, D., 1998. Environmental Kuznets curves-real progress or passing the buck? A case for consumptionbased approaches. Ecological Economics 25, 177-194.

Schmidheiny, S., 1992. Changing Course. MIT Press, Boston, MA. Sun, J.W., 2004. The impact of changing energy mix on CO2 emissions: a case from CO2 emissions in the OECD 1971-2000. Energy Sources 26, 915926.

Waggoner, P.E., Ausubel, J.H., 2002. A framework for sustainability science: A renovated IPAT identity. Proceedings of the National Academy of Science 99, 7860-7865.

Welford, R., 1998. Corporate environmental management, technology and sustainable development: postmodern perspectives and the need for a critical research agenda. Business Strategy and the Environment 7 (1), 1-12.

World Business Council for Sustainable Development, 2000. Ecoefficiency: Creating More Value with Less Impact. WBCSD, Cobchess-Geneva.

York, R., 2005. Kyoto protocol participation: a demographic explanation. Population Research and Policy Review 24, 513-526.

York, R., Rosa, E.A., Dietz, T., 2003. STIRPAT, IPAT and ImPACT: analytic tools for unpacking the driving forces of environmental impacts. Ecological Economics 46 (3), 351-365. 